https://helda.helsinki.fi

Benzodiazepines and Z-drugs may cause prolonged cognitive issues in young adults - are hypnotics not only a geriatric dilemma?

Puustinen, Juha

2018-12

Puustinen , J 2018 , ' Benzodiazepines and Z-drugs may cause prolonged cognitive issues in young adults - are hypnotics not only a geriatric dilemma? ' , Sleep Medicine , vol. 52 , pp. 219-220 . https://doi.org/10.1016/j.sleep.2018.08.011

http://hdl.handle.net/10138/308810

https://doi.org/10.1016/j.sleep.2018.08.011

publishedVersion

Downloaded from Helda, University of Helsinki institutional repository.

This is an electronic reprint of the original article.

This reprint may differ from the original in pagination and typographic detail.

Please cite the original version. 
Editorial

\section{Benzodiazepines and Z-drugs may cause prolonged cognitive issues in young adults - are hypnotics not only a geriatric dilemma?}

The risks of benzodiazepines (BZDs) in the elderly are well known. BZD use has been associated with increased risks of fallings, fractures, mobility disabilities, deteriorated activities of daily living, traffic accidents, chemical restraining and mortality [1-6]. Moreover, acute psychocognitive and motor complications related to BZDs have been shown in short-term, randomized, controlled trials [7]. In addition, the newer 'Z-drugs' such as zopiclone, zolpidem or zaleplone have not been shown to be better than conventional BZDs [8]. Even after adjusting for possible protopathic bias, longterm BZD use in the elderly has been associated with significantly higher risk of cognitive decline and dementia compared to nonusers [9].

Currently, the underlying neural mechanisms linking how BZDS and Z-drugs might cause the long-term cognitive defects and dementia remain unknown. In a mice experiment [10], BZDs increased neurotoxic amyloid beta, a key protein involved in the neuropathology of Alzheimer's disease. Conversely, a human study [11] could not replicate the finding of increased neuronal protein accumulations.

Currently, geropharmacologic guidelines do not recommend the long-term BZD use in the elderly [12,13]. Moreover, practical and inexpensive interventions can be used to reduce long-term use in older adults [14-16]. Both notable and worrisome, studies have shown that in the elderly [17,18] - or in the middle-aged [19] the expected cognitive abilities are not recovered after BZD withdrawal.

But are the issues related to BZDs and Z-drugs limited only to the aged?

Authorities in many countries have accepted short-term use of short-acting BZDs in appropriate patients. Residual effects of hypnotic use on driving abilities have been reported to be conflicting or related to the half-life of drug used; while hypnotics with short-half lives have been considered safe, medium- and longacting have not [20].

To question the idea of non-existing or low risk of cognitive residual effects in the young adults, the current issue of Sleep Medicine has published a double-blind, randomized controlled trial "Effects of zolpidem/triazolam on cognitive performance $12 \mathrm{~h}$ after acute administration" by Matsunaga and colleagues [21]. Their article reports the short-term follow-up results of an experimental trial being a valuable contribution to clinical BZD literature. Either a placebo or active hypnotic drug (zolpidem or triazolam) was given to healthy, young male volunteers (mean age $23.4 \pm 3.2$ years $)$ in a small cohort $(N=13)$. The authors objectively measured the sleep parameters and the cognitive performance $12 \mathrm{~h}$ after administration of hypnotics in three time-points. The time-interval between individual measures was at least five days.

The results of Matsunaga and colleagues showed that sleep efficiency was increased after hypnotic drug when compared to placebo. Cognitive performance measured by a digit symbol subtraction test was deteriorated even after $12 \mathrm{~h}$ after hypnotic administration, while the psychomotor vigilance test remained unchanged. Therefore, the authors concluded that cognitive functions remain deteriorated $12 \mathrm{~h}$ after hypnotic drug administration whereas sleepiness disappears.

The experimental setting is sound, yet includes some flaws. First, the sample size is small and, thus, their study can be considered as a well-designed experimental pilot study. Second, there is a risk of bias as all participants received placebo on the first night and all three measurement points were not completely randomized and blinded followed by repetitive measuring. However, the authors had controlled these risks of biases by blinding the participants and researchers using identical tablets. Moreover, learning effects in repetitive testing was low as the tests were changed during the test protocol.

Overall, the findings by Matsunaga and colleagues are disturbing and may reveal a huge risk when employees in high risk occupations have taken hypnotics thought to be safe prior to their working shifts. According to this trial the risks of errors and accidents are increased because there is still cognitive deterioration even when not feeling tired.

To increase the external validity, trials on residual cognitive effects of BZDs and Z-drugs should be replicated in larger young and middle-aged fully randomized and controlled cohorts. Specifically, practical tests in driving, aviation and nuclear power plant simulators in addition to other high-risk occupations should be performed in order to find out the clinical meaning of the deteriorated neuropsychological tests. If the results of future trials are uniform with the results of the present study by Matsunaga and colleagues, it is time to re-write the guidelines concerning BZD use in high-risk occupations.

To understand on the biological level why cognition remains deteriorated after hypnotic exposure, the neural mechanisms and neurotoxic changes need to be explored - not only studying cerebral protein deposits - but also functionally the neuronal circuits and brain plasticity before, during and after BZD use.

Finally, benzodiazepines may be a cognitive risk factor - not only among the elderly - but in young adults as well. 


\section{Conflict of interest}

The ICMJE Uniform Disclosure Form for Potential Conflicts of Interest associated with this article can be viewed by clicking on the following link: https://doi.org/10.1016/j.sleep.2018.08.011.

\section{References}

[1] Hartikainen S, Lönnroos E, Louhivuori K. Medication as a risk factor for falls: critical systematic review. J Gerontol A Biol Sci Med Sci 2007;62(10):1172-81.

[2] Nurminen J, Puustinen J, Piirtola M, et al. Psychotropic drugs and the risk of fractures in old age: a prospective population-based study. BMC Publ Health 2010;10:396. https://doi.org/10.1186/1471-2458-10-396.

[3] Gray SL, LaCroix AZ, Hanlon JT, et al. Benzodiazepine use and physical disability in community-dwelling older adults. J Am Geriatr Soc 2006;54(2): 224-30.

[4] Orriols L, Philip P, Moore N, et al. Benzodiazepine-like hypnotics and the associated risk of road traffic accidents. Clin Pharmacol Ther 2011;89(4):595-601.

[5] Nurminen J, Puustinen J, Kukola M, et al. The use of chemical restraints for older long-term hospital patients: a case report from Finland. J Elder Abuse Negl 2009;21(2):89-104.

[6] Obiora E, Hubbard R, Sanders RD, et al. The impact of benzodiazepines on occurrence of pneumonia and mortality from pneumonia: a nested casecontrol and survival analysis in a population-based cohort. Thorax 2013;68(2):163-70. https://doi.org/10.1136/thoraxjnl-2012-202374.

[7] Glass J, Lanctôt KL, Herrmann N, et al. Sedative hypnotics in older people with insomnia: meta-analysis of risks and benefits. BMJ 2005;331(7526):1169.

[8] Huedo-Medina TB, Kirsch I, Middlemass J, et al. Effectiveness of nonbenzodiazepine hypnotics in treatment of adult insomnia: meta-analysis of data submitted to the Food and Drug Administration. BMJ 2012;345: e8343.

[9] Penninkilampi R, Eslick GD. A systematic review and meta-analysis of the risk of dementia associated with benzodiazepine use, after controlling for protopathic bias. CNS Drugs 2018. https://doi.org/10.1007/s40263-018-0535-3.

[10] Tan S, Metzger DB, Jung ME. Chronic benzodiazepine suppresses translocator protein and elevates amyloid $\beta$ in mice. Pharmacol Biochem Behav 2018;172: 59-67. https://doi.org/10.1016/j.pbb.2018.07.005.

[11] Chung JK, Nakajima S, Shinagawa S, et al. Benzodiazepine use attenuates cortical $\beta$-amyloid and is not associated with progressive cognitive decline in nondemented elderly adults: a pilot study using F18-Florbetapir positron emission tomography. Am J Geriatr Psychiatr 2016;24(11):1028-39. https:/ doi.org/10.1016/j.jagp.2016.04.013.
[12] Dimitrow MS, Airaksinen MS, Kivelä SL, et al. Comparison of prescribing criteria to evaluate the appropriateness of drug treatment in individuals aged 65 and older: a systematic review. J Am Geriatr Soc 2011;59(8): 1521-30. https://doi.org/10.1111/j.1532-5415.2011.03497.x.

[13] American Geriatrics Society. Updated beers criteria for potentially inappropriate medication use in older adults. J Am Geriatr Soc 2015. https://doi.org 10.1111/jgs.13702.

[14] Gould RL, Coulson MC, Patel N, et al. Interventions for reducing benzodiazepine use in older people: meta-analysis of randomised controlled trials. $\mathrm{Br}$ J Psychiatry 2014;204(2):98-107. https://doi.org/10.1192/bjp.bp.113. 126003.

[15] Lähteenmäki R, Puustinen J, Vahlberg T, et al. Melatonin for sedative withdrawal in older patients with primary insomnia: a randomized double-blind placebo-controlled trial. Br J Clin Pharmacol 2014;77(6):975-85.

[16] Puustinen J, Lähteenmäki R, Nurminen J, et al. Long-term persistence of withdrawal of temazepam, zopiclone, and zolpidem in older adults: a 3-year follow-up study. BMC Geriatr 2018;18(1):142. https://doi.org/10.1186/ s12877-018-0829-9.

[17] Curran HV, Collins R, Fletcher S, et al. Older adults and withdrawal from benzodiazepine hypnotics in general practice: effects on cognitive function, sleep, mood and quality of life. Psychol Med 2003;33(7):1223-37.

[18] Puustinen J, Lähteenmäki R, Polo-Kantola P, et al. Effect of withdrawal from long-term use of temazepam, zopiclone or zolpidem as hypnotic agents on cognition in older adults. Eur J Clin Pharmacol 2014;70(3):319-29. https:/ doi.org/10.1007/s00228-013-1613-6.

[19] Barker MJ, Greenwood KM, Jackson M, et al. Persistence of cognitive effects after withdrawal from long-term benzodiazepine use: a meta-analysis. Arch Clin Neuropsychol 2004;19(3):437-54.

[20] Roth T, Eklov SD, Drake CL, et al. Meta-analysis of on-the-road experimental studies of hypnotics: effects of time after intake, dose, and half-life. Traffic Inj Prev 2014;15(5):439-45. https://doi.org/10.1080/15389588.2013.830211.

[21] Matsunaga Y, Tagaya H, Fukase Y, et al. Effects of zolpidem/triazolam on cognitive performance 12 hours after acute administration. Sleep Med 2018;52:213-8.

Juha Puustinen

University of Helsinki, Division of Pharmacology and Pharmacotherapy, Satakunta Hospital District, Unit of Neurology, Social Security Center of Pori, Hospital Services, Finland E-mail address: juhpuu@utu.fi.

Available online 31 August 2018 